\title{
Effects of EM Technology on Urban River Wastewater Purification
}

\author{
Y.L. Shao ${ }^{1}$, Jing $\mathrm{Ma}^{1}$,Yao Lu${ }^{1}$, Junqi Mao ${ }^{1}$, Haochen $\mathrm{Yan}^{1}$,L.H. Chen ${ }^{1,2}$ \& \\ X.H. Shao ${ }^{2,3, *}$
}

${ }^{1}$ College of Water Conservancy and Hydropower Engineering, Hohai University, Nanjing, 210098, China.

${ }^{2}$ Key Laboratory of Efficient Irrigation-Drainage and Agricultural Soil-Water Environment in Southern China of Ministry of Education, Hohai University, 210098, China.
${ }^{3}$ Nanjing Ning-ya Environmental Science and Technology Limited Company, Nanjing 210036, PR China.

a2540925761@qq.com, ${ }^{b} 532697294 @ q q . c o m,{ }^{c} 137190427 @ q q . c o m{ }^{d} 1714509635 @ q q . c o m,{ }^{e} 70457$

0493@qq.com, ${ }^{\mathrm{f}}$ chenlihua2001@163.com, ${ }^{9}$ shaoxiaohou@163.com

${ }^{*}$ corresponding author

Keywords: EM technology, polluted urban river, water restoration, pollutants purification Abstract: Considering the various experimental conditions, we carried on the study applying EM (Effective Micro-organisms) stock solution on polluted urban river water purification. Experimental results showed that EM technology on restoration of urban polluted water bodies had a more significant effect, the accumulated removal rate of $\mathrm{COD}_{\mathrm{Mn}}$, ammonia and phosphate being $64.5 \%$, $87.0 \%$ and $88.5 \%$ respectively for the treatment of EM concentration of $0.1 \%$. The higher concentration of dissolved oxygen in wastewater system, there would be a better degradation effect of $\mathrm{COD}_{\mathrm{Mn}}$. Test results and the pollutants removal trends in situ were consistent with the results obtained from lab experiment.

\section{Introduction}

With the continuous growth of the national economy level, China has and will further accelerate the process of urbanization ${ }^{[1]}$. As a key carrier of freshwater resources and the environment, urban rivers and lakes are important factors influencing the urban style and beautifying the urban environment. Although laws and regulations in the field of controlling polluted water have been formulated, the water environment pollution around us is getting worse as a result of the urban expansion and the rapid population growth. Therefore, effective water restoration measures are in urgent need to clean water environment, and should be taken to prevent the restored water bodies from deteriorating again ${ }^{[2]}$.

EM (Effective Micro-organisms) is a variety of mixed microbial communities, of which the key is photosynthetic bacteria, coexisting and reproducing with nitrogen-fixing bacteria, then using appropriate proportion and unique fermentation process, carefully screening out the aerobic and anaerobic micro-organisms to cultivate ${ }^{[1-4]}$. The useful substances and secretions produced during the growth of various micro-organisms become the substrate and raw materials into the growth of microbial populations, through the mutual relationship between the proliferations of this symbiosis, a stable complex microbial system is formed, playing a variety of functions ${ }^{[2]}$.

EM water restoration technology is based on the antimicrobial compound in the EM, through a specific process, to separate, domesticate and enrichment microorganisms, creating the right 
conditions to maximize the elimination of the degradation of pollutants in water bioremediation technology ${ }^{[3]}$. In this paper, EM stock solution was used to study its purification effect on urban river wastewater in lab and in situ experiments.

\section{Materials and methods}

Materials. EM stock solution was purchased from EMRO Environmental Biological Technology (Nanjing) Co., LTD. Wastewater samples were got from a urban river in HengXi Town, Nanjing. It had the water quality status of $17.89 \mathrm{mg} / \mathrm{L} \mathrm{COD}_{\mathrm{Mn}}, 10.03 \mathrm{mg} / \mathrm{L}$ ammonia nitrogen and $1.34 \mathrm{mg} / \mathrm{L}$ phosphate.

Experimental settings. Considering different concentrations of EM stock solution, different aeration and water pollution levels in wastewater systems, we tested the restoration performance of EM stock solution for polluted urban river water through the experimental determination. Specific implementation plans are as follows: The EM stock solution concentration in three different ratios of $0.1 \%$ o, $0.3 \%$ o $0.7 \%$ with wastewater was set to conduct the test under aeration with dissolved oxygen concentration at 4 6mg/L. Under the condition of EM concentration of $0.3 \%$, the effect on polluted water biodegradation test was conducted with original urban river water condition (dissolved oxygen concentration at $0 \sim 1 \mathrm{mg} / \mathrm{L}$ ), micro-aeration (dissolved oxygen concentration at $2 \sim 3 \mathrm{mg} / \mathrm{L}$ ) and aeration (dissolved oxygen concentration at 4 to $6 \mathrm{mg} / \mathrm{L}$ ) respectively. With the EM concentration of $0.3 \%$, dissolved oxygen at $2 \sim 3 \mathrm{mg} / \mathrm{L}$ or so, the test was done to check the effects of bioremediation on polluted water of different loads while adding EM. A typical polluted river with water quality status of CODMn17.89mg/L, ammonia nitrogen $10.03 \mathrm{mg} / \mathrm{L}$, and phosphate $1.34 \mathrm{mg} / \mathrm{L}$ was selected to observe the removal rates of $\mathrm{EM}$ on water $\mathrm{COD}_{\mathrm{Mn}}$, ammonia and phosphate during the aeration and the addition of $0.3 \%$ EM.

Determination methods. Chemical Oxygen Demand $\left(\mathrm{COD}_{\mathrm{Mn}}\right)$ was measured by acidity method. $\mathrm{NH}_{4}{ }^{+}-\mathrm{N}$ was measured by the Nessler reagent spectrophotometry; TP was measured by the molybdate spectrophotometry.

\section{Analysis of results and discussion}

EM concentration on removal of major pollutants. The biological degradation of bacteria in contaminated water under different EM concentrations was shown in Figure 1. The results showed that the best removal rate of $\mathrm{COD}_{\mathrm{Mn}}$ was $64.5 \%$ for the treatment of EM concentration of $0.1 \%$, with $12.3 \%$ and $34.44 \%$ higher than the concentration of $0.3 \%$ and $0.7 \%$ respectively. Because of the high $\mathrm{COD}_{\mathrm{Mn}}$ in compound broth medium of EM, the larger the concentration of EM, the higher $\mathrm{COD}_{\mathrm{Mn}}$ in wastewater system would be. Therefore, $\mathrm{COD}_{\mathrm{Mn}}$ removal rate did not increase synchronously with the increase of compound broth addition of EM. 


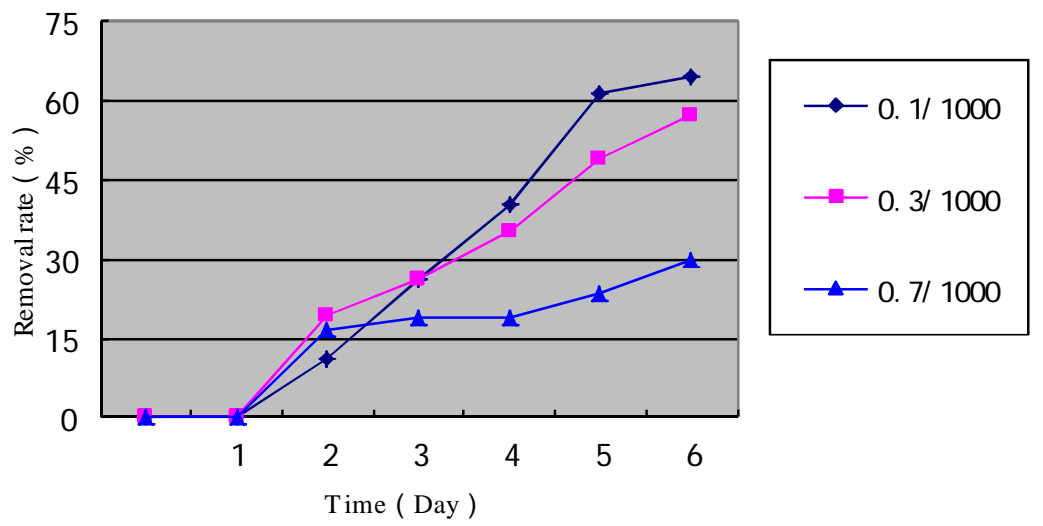

Figure 1 Different dosage on the removal of $\mathrm{COD}_{\mathrm{Mn}}$

Effects of EM concentrations on ammonia removal rate in the micro-polluted urban river water were shown in Figure 2. The results showed that the best removal rate of ammonia nitrogen was $88 \%$ for the treatment of EM concentration of $0.1 \%$. It was believed nitrification could be carried out very well while the $\mathrm{BOD}_{5}$ concentration was less than $20 \mathrm{mg} / \mathrm{L}^{[4]}$ because nitrification was mainly done by nitrifying bacteria. If $\mathrm{COD}_{\mathrm{Mn}}$ concentration is high, the growth of heterotrophic bacteria will be a substantial advantage to inhibit the growth and reproduction of nitrifying bacteria. Therefore, the higher adding of EM can cause higher $\mathrm{COD}_{\mathrm{Mn}}$ concentration in wastewater system and ammonia nitrogen removal rate will be decreased.

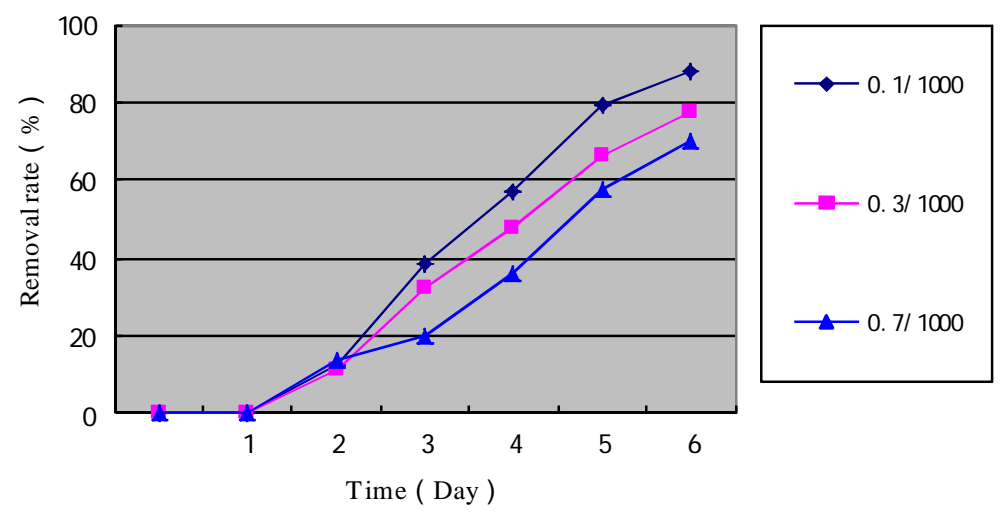

Figure 2 Different dosage on the removal of ammonia

Effects of EM concentrations on phosphate removal rate in the micro-polluted urban river water were shown in Figure 3. The results showed that the higher concentration of EM stock solution, the better the effect of phosphate removal rate. The reason might be that the lower amount of EM resulted in Phosphate-Accumulating-Bacteria (PAOs) difficult to reproduce rapidly to become the dominant bacteria, with the performance of poor phosphorus removal. Then with the increasing adding of compound bacteria of EM, the number of PAOs increased, therefore biological phosphorus removal effect will also be improved ${ }^{[5 \sim 6]}$. 


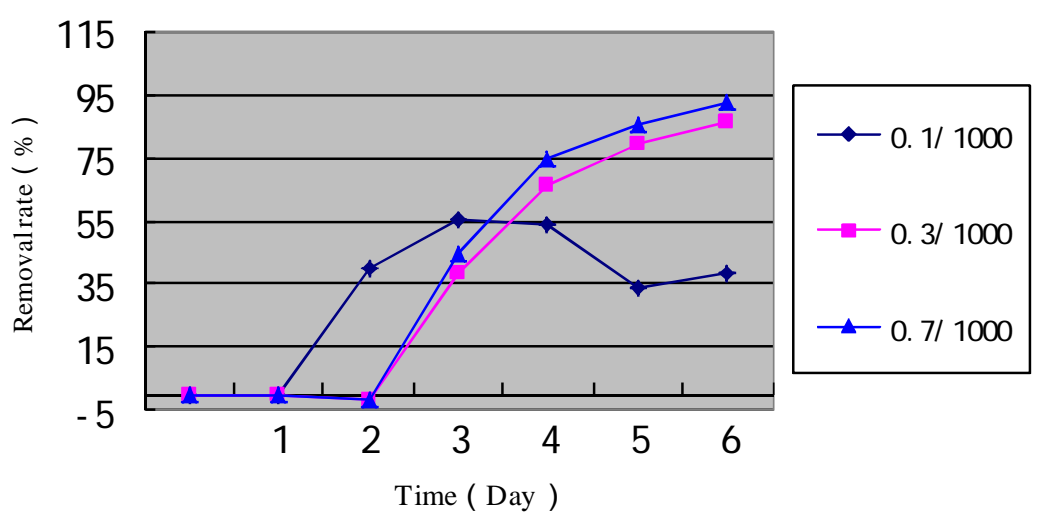

Figure 3 Diferent dosage on the removal of phophate

EM on degradation of $\mathbf{C O D}_{\mathrm{Mn}}$ under different aeration levels. Figure 4 showed the removal process of $\mathrm{COD}_{\mathrm{Mn}}$ in micro-polluted urban river water over time under different levels of dissolved oxygen. Figure 5 indicated that the higher concentration of dissolved oxygen in water, the better degradation effect of $\mathrm{COD}_{\mathrm{Mn}}$. This was mainly due to a great relationship between the effect of bioremediation and electron acceptor concentration and type. In the contaminant biodegradation process the electron acceptor was needed to accept molecular electronics produced by the pollutants degradation. During the biological oxidation-reduction reaction dissolved oxygen was the main electron acceptor ${ }^{[7-8]}$.
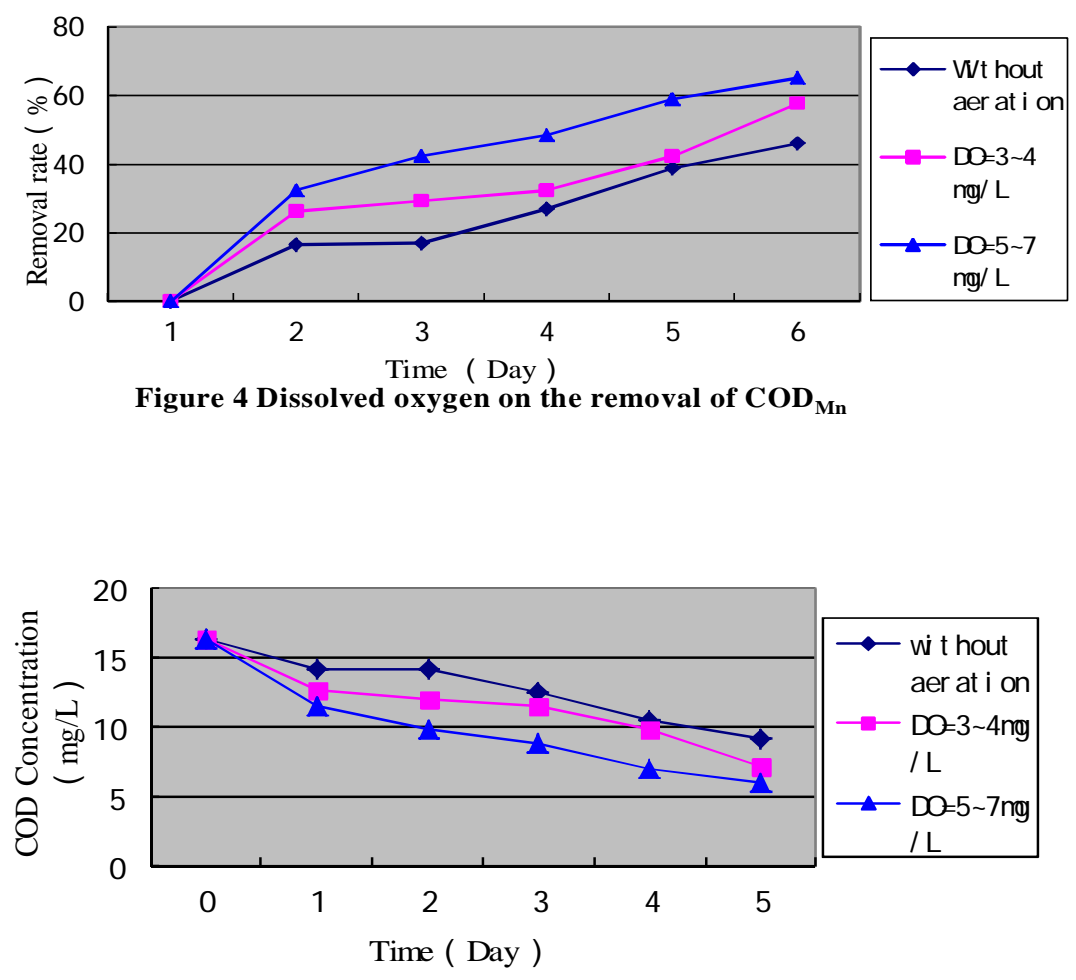

Figure 5 Dissolvedoxygen on the removal of $\mathrm{COD}_{\mathrm{Mn}}$

EM effects of purification on polluted water of different loads. While the concentration of 
EM was $0.3 \%$, and DO was $2 \sim 3 \mathrm{mg} / \mathrm{L}, \mathrm{COD}_{\mathrm{Mn}}$ degradation effects of EM on polluted waters were shown in Table 1. When $\mathrm{COD}_{\mathrm{Mn}}$ concentration in raw water was lower, EM played no significant role in promoting the removal effect of $\mathrm{COD}_{\mathrm{Mn}}$. It might be the low concentration of pollutants in raw water which resulted in its insufficient supply of exogenous microbial growth and reproduction. With a large number of cells in a poor nutritional condition, the need for endogenous to obtain metabolic energy made the low degradation rate of pollutants. Furthermore, low loads in raw water showed no significant biological degradation effect due to the $\mathrm{COD}_{\mathrm{Mn}}$ value changes caused by adding EM.

Table 1 EM effects of purification on polluted water of different loads

\begin{tabular}{|c|c|c|}
\hline $\begin{array}{c}\mathrm{COD}_{\mathrm{Mn}} \text { Concentration } \\
(\mathrm{mg} / \mathrm{L})\end{array}$ & $\begin{array}{c}\text { Highest removal } \\
\text { rate }(\%)\end{array}$ & $\begin{array}{c}\text { Removal of reference } \\
\text { Samples }(\%)\end{array}$ \\
\hline 17.89 & 68.30 & 38.50 \\
\hline 16.4 & 64.50 & 49.70 \\
\hline 14.2 & 45.00 & 32.00 \\
\hline 8.1 & 33.00 & 30.80 \\
\hline
\end{tabular}

The results showed that adding EM had a significant effect for water bioremediation when raw water concentration was more than $14.2 \mathrm{mg} / \mathrm{L}$. Comparing with the removal rates of $32 \%, 49.7 \%$ and $38.5 \%$ of the same period of the control groups without adding EM, the highest removal rates reached $45 \%, 64.5 \%$ and $68.3 \%$ respectively, which had a significant increase.

EM Technology on Contaminated Water Restoration in situ. A typical polluted river has the water quality status of $\mathrm{COD}_{\mathrm{Mn}} 17.89 \mathrm{mg} / \mathrm{L}$, ammonia nitrogen $10.03 \mathrm{mg} / \mathrm{L}$, and phosphate $1.34 \mathrm{mg} / \mathrm{L}$. During the aeration and the addition of $0.3 \%$ EM , the removal rates of EM on water $\mathrm{COD}_{\mathrm{Mn}}$, ammonia and phosphate were shown in Figure 6.

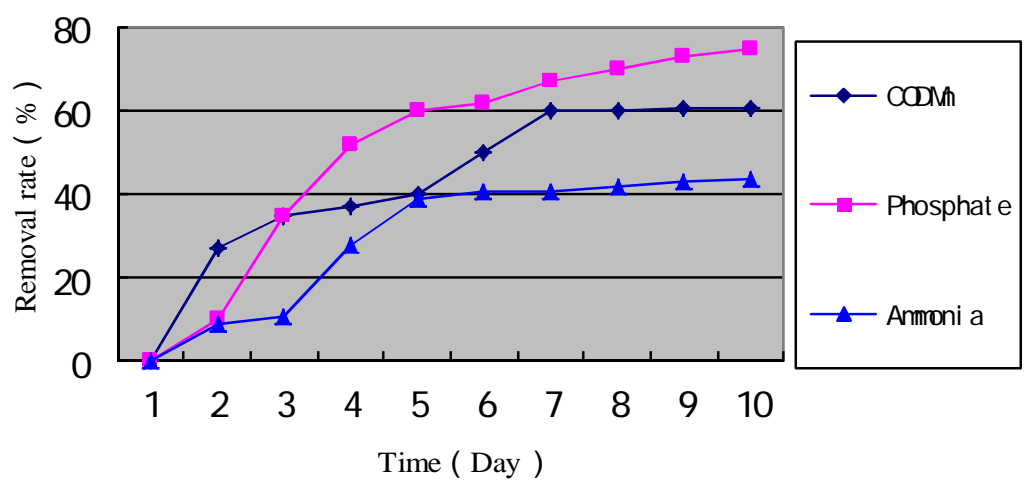

Figure 6 Biological degradation of compound bacterium

Figure 6 showed that after adding EM, COD ${ }_{\mathrm{Mn}}$, ammonia and phosphate removal rate showed a rising trend with time. The rates of $\mathrm{COD}_{\mathrm{Mn}}$ and ammonia removal were stable after the addition of EM in six days, about $60 \%$ and $43 \%$ respectively. Removal rate of phosphate reached $75 \%$ after adding EM in nine days. Test results and removal trends in situ were consistent with the above results obtained from lab experiment.

\section{Conclusions}

The results showed EM had the functions of the rapid pollutants decomposition rate and environmental protection for urban river and the accumulated removal rate of $\mathrm{COD}_{\mathrm{Mn}}$, ammonia 
and phosphate was $64.5 \%, 87.0 \%$ and $88.5 \%$ for the treatment of EM concentration of $0.1 \%$. The higher concentration of dissolved oxygen in wastewater system, there would be a better degradation effect of $\mathrm{COD}_{\mathrm{Mn}}$. It was indicated that the highest removal rates reached $45 \%, 64.5 \%$ and $68.3 \%$ respectively compared with the removal rates of $32 \%, 49.7 \%$ and $38.5 \%$ of the same period of the control groups without adding EM when raw water concentration was more than $14.2 \mathrm{mg} / \mathrm{L}$. Test results and removal trends in situ were consistent with the results obtained from lab experiment.

\section{Acknowledgements}

This work was supported by the National Level Undergraduate Innovation Training Plan Project (201510294010), the Water Science and Technology Project of Jiangsu Province (2014049), Science and Technology Research Project of Jiangsu (BE 2015705).

\section{References:}

[1] Wang Ping. A Systemtic Study on Application of Effective Micro Organism(EM) in the Field of Water Treatment [J]. Master Thesis, Hohai University. 2003.5:25-26

[2] Kang Bai. Micro-ecology [M]. Dalian Publishing. 1998:106-110

[3] Qiao Junjing et al. Application of Effective Micro-organisms Technology in Wastewater Treatment[J]. Resource Development \& Market. 2008.11:968-970

[4] Dangcong P, Bernet $\mathrm{N}$ et al. Effcets of oxygen supply methods on the Performance of a Sequencing Batch Reactor for high ammonium nitrification[J]. Water Environ.Res.,2000,72(2):195-200

[5] Shao Qing. EM on Common Pollutants in Sewage Removal [J]. China Water \& Wastewater. 2001,17(3):74-76

[6] Siegrist H,Boller M. Effects of the Phosphate Ban on Sewage Treatment[J]. EAWAG News, 1997,42E:9-11

[7] Shao Qing, Luo Wensheng. Research on High Efficiency and Low Energy Cost of Adding EM to Sequencing Batch Reactor (SBR) on the Pollutant Removal in the Municipal Sewage [J]. China Rural Nater and Hydropower. 2002,10:27-30

[8] Richard O,Mines J R et al. Bionutrient removal with a sequencing batch reactor[J].Water Air and soil Pollution,1998,107(1):81-89 